\title{
Índices de urbanização e urbanidade em perspectiva histórica: São Paulo, 1798-1930
}

\author{
BUENO, Beatriz Piccolotto Siqueira
}

\begin{abstract}
Resumo
A historiografia recente sobre a história da urbanização no Brasil vem formulando novos problemas, variáveis de análise e incluindo novos atores no debate, valendo-se das tecnologias da informática (SIG) para espacialização de processos sociais no tempo e mapeamento de questões em diversas escalas de observação. Estudos estão dando contornos e colorido a camadas outrora imprecisas. Neste ensaio, recortamos alguns resultados das pesquisas que estamos desenvolvendo nos projetos A cidade como negócio: mercado imobiliário em São Paulo (1809-1914) e Índices de urbanização e urbanidade em perspectiva histórica: São Paulo, 1765-1914, ambos financiados pelo CNPq, e no livro São Paulo: um novo olhar sobre a história. A evolução do comércio de varejo e as transformações da vida urbana (2012). Recuamos no tempo e cotejamos Censos e Décimas Urbanas com a documentação da Série Obras Particulares do Arquivo Histórico de São Paulo (AHSP), dos almanaques, anúncios de jornais, fotos e plantas antigas, com vistas a perceber mudanças nos índices de urbanização e de urbanidade em perspectiva histórica de longa duração. Ampliamos o escopo para espacializar o processo de transformação da cidade, com foco em aspectos materiais (programas edilícios, tipologias, áreas mais e menos verticalizadas), sociais (proprietários, inquilinos, usos e usuários) e imobiliários (áreas mais e menos valorizadas), diferenciando, por exemplo, as modalidades de comércio, identificando o lugar dos serviços e reconstituindo territorialidades perdidas no tempo e assim índices de urbanidade, numa metodologia até então inexplorada pela historiografia.
\end{abstract}

Palavras-chave: São Paulo. História da Urbanização. Índices de Urbanidade. Séculos XVIII-XX.

\begin{abstract}
:
Recent historiography on the history of urbanization in Brazil has been formulating new problems and variables for analysis as well as involving new actors in the debate. Information technology (SIG) has been used to spatialize social processes in time and map issues on various scales of observation. Studies are now providing outlines and colour for previously vague layers. This paper focuses on some of the research results obtained by the projects 'The city as business: the real estate market in São Paulo (1809-1914)' and 'Levels of urbanization and urbanity in historical perspective: São Paulo, 1765-1914', both funded by CNPq, and outlined by the 2012 book São Paulo: um novo olhar sobre a história - a evolução do comércio de varejo e as transformações da vida urbana (in English, 'São Paulo: a new look at its history - the evolution of retailing and the transformations of urban life'). We went back in time to compare urban censuses and tithes with documentation from the Obras Particulares (in English, Private Buildings) series of São Paulo's Municipal Historical Archives (AHSP), as well as from almanacs, newspaper advertisements, photos, and old plans, to detect changes in levels of urbanization and urbanity from a long-term perspective. The scope was broadened to spatialize the process of the city's transformation, focusing on material aspects (building programs, typologies, most and least verticalized areas), social aspects (landlords, tenants, uses, and users), and real estate aspects (most and least expensive areas). The analysis distinguishes, for instance, types of commerce, identifies service locations, and reconstitutes lost territorialities and thus urbanity levels, applying a methodology as yet unexplored by historiography.
\end{abstract}

Keywords: São Paulo. History of Urbanization. Urbanity Levels. 18th-20th centuries. 


\section{Introdução}

Sistemas de Informações Geo-Históricas (SIGs) permitem reconstituir cenários na longa duração. No âmbito de um programa de cooperação internacional entre a USP e a Universidade de Lyon - COFECUB $2013^{1}$ - estamos iniciando um projeto de transferência de know-how e capacitação técnica de pesquisadores na ferramenta SIG. Os SIG Históricos são fundamentais na espacialização de banco de dados, viabilizando a elaboração de cartografias regressivas e temáticas - quadra a quadra, rua a rua, lote a lote -, cruzando informações textuais e visuais variadas, reconstituindo perfis tanto materiais como sociais. Nossa proposta ancora-se no legado de outro projeto de pesquisa em Políticas Públicas (FAPESP, 2006- 2010), no qual coordenamos junto com Nestor Goulart Reis a informatização de parte dos desenhos arquitetônicos e dados da Série Obras Particulares ${ }^{2}$ do AHSP (19061914), cujos resultados estão na internet (www. projetosirca.com.br) e muito facilitam nossa empreitada atual. Esboçamos aqui, em linhas gerais, nossa contribuição neste e noutros projetos que estamos desenvolvendo sobre São Paulo, apresentando os resultados parciais de uma metodologia ainda inédita.

Numa intersecção entre História da Urbanização (REIS, 1999) e História da Cultura Material (MENESES, 1980, 1990), a produção social do espaço urbano tem sido objeto de nossas pesquisas, privilegiando séries documentais heterogêneas e conexas pouco exploradas pela historiografia, alinhavadas em perspectiva histórica de longa duração, lote a lote. Propomo-nos agora a recuar um pouco mais no tempo, voltando ao século XVIII, focalizando aspectos do mercado imobiliário rentista em meio a outros, tais como variáveis que nos permitem identificar a dinâmica do processo de urbanização (a partir de quando se acelerou) e mudanças nos índices de urbanidade do período colonial à Primeira República. O papel da iniciativa privada na produção material da cidade e as mudanças na tessitura urbana continuam sendo nossas preocupações, só que acrescidas de questões como as continuidades e rupturas no perfil dos proprietários dos imóveis, no perfil dos usuários e usos, na natureza do comércio e dos comerciantes, na

\footnotetext{
1. "Dinâmicas de urbanização e representações espaciais: abordagem geo-histórica dos territórios com SIG" - USP COFECUB 2013. Equipe: Profs. Drs. Iris Kantor (DH-FFLCH-USP, coordenadora), Beatriz Bueno (FAUUSP), Fernanda Padovesi (DG-FFLCH-USP), Jaime Oliva (IEB-USP), Bernard Gauthier (Université Jean Moulin - Lyon), Enalli di Biagi (Université Jean Moulin - Lyon).

2. Conjunto dos projetos arquitetônicos submetidos à aprovação da Prefeitura por particulares, exigidos desde 1893.
}

natureza dos programas edilícios implantados (mesclando moradia, comércio e serviços), na natureza das construções e o quanto individualmente desenharam uma paisagem urbana visualmente nova e bem construída. Tais preocupações foram parcialmente contempladas no livro São Paulo: um novo olhar sobre a História. A evolução do comércio de varejo e as transformações na vida urbana (2012), merecedor do Prêmio José Celestino Bourroul-2013 da APH.

Advogamos a tese de que boa parte das renovações foi obra da iniciativa privada, orquestrada e induzida pelo poder público por meio de pormenorizada legislação. Malgrado motivados pelos lucros prometidos por um mercado imobiliário aquecido, os resultados foram, a nosso ver, de altíssima qualidade, fruto do comprometimento com a cidade de todos os elos da cadeia produtiva. Tratava-se de um excelente negócio para os proprietários construírem imóveis cada vez mais verticalizados e multifuncionais, pois havia demanda, mas as obras foram feitas com projetos esmerados, a maioria assinados pelos melhores profissionais da época, edificados em conformidade com uma legislação urbanística e sanitária que zelava pela qualidade do produto (garantindo pés-direito generosos, aberturas fartas, materiais construtivos de primeira). Os memoriais e projetos arquitetônicos hoje reunidos na Série Obras Particulares do AHSP alicerçam tais afirmações. Nota-se, além do comprometimento dos proprietários com a cidade, o mesmo ocorrer com os usuários dos imóveis. No centro, foi estabelecido um comércio refinado pelas mãos de agentes estrangeiros que se notabilizaram pela qualidade dos estabelecimentos e produtos ali vendidos (BARBUY, 2006; BUENO, 2012). Embora os estrangeiros não tivessem inicialmente poder aquisitivo para comprar e renovar imóveis no perímetro central, foram inquilinos comprometidos na construção de uma imagem de cidade "moderna e cosmopolita", obviamente orquestrados pela municipalidade que lhes concedia "licenças e alvarás" para realizarem seus negócios.

O resultado hoje é um importante patrimônio em vias de dilapidação que resiste ao tempo galhardamente a despeito de tanto descaso. Resiste porque foi feito sólido, porque foi obra de uma gente antiga que tinha apreço pela cidade e lhe retribuía com seu trabalho, mesmo lucrando com isso. Esse legado de comprometimento e zelo pela cidade em diversos níveis merece ser resgatado do esquecimento e preservado, assim como o patrimônio material que lhe é correlato. Eram tempos em que construir uma certa "cidade" estava acima dos interesses individuais, e todos - iniciativa privada e poder público 
- empenharam-se na qualidade de suas ações individuais. As fachadas dos imóveis do centro estampam nomes de famílias e engenheiros-arquitetos, eternizados na produção material da cidade. A qualidade dos resultados abunda nas fotos e cartões postais da época, motivo de orgulho e divulgação - afinal, tratava-se da "Metrópole do Café" coletivamente construída em menos de um século. Os bons resultados se estenderam também aos bairros envoltórios, tanto os destinados às elites, como os destinados às camadas médias e baixas. Mestrados recentes, como o de Sheila Schneck (2010) sobre o bairro do Bexiga e de Lindener Pareto Júnior (2011) sobre os práticos licenciados, dão a medida da qualidade das construções nas áreas mais afastadas, cuja produção envolveu os setores médios da população e projetos assinados por construtores não diplomados.

\section{Recuo estratégico}

O recuo aos Setecentos é metodologicamente estratégico, por permitir mensurar esse processo de mudança acelerado a partir de fins dos Oitocentos. Quando cotejamos os dados estatísticos dos Censos (1765, 1767, 1776, 1798, 1802, 1804, 1814, 1815, 1817, 1822, 1836, 1854, 1872 ), com os dados dos nossos primeiros impostos prediais (Décimas Urbanas 1809, 1829, 1876, 1886/1887, 1888/1889), dos almanaques (1857, 1884 e 1890), dos jornais e dos projetos arquitetônicos do AHSP (1906-1914), e os espacializamos nas plantas da cidade (1774, 18441847, 1881, 1893, 1897, 1905, 1911, 1916 e 1930), vemos a mutação progressiva do velho tecido urbano de São Paulo, especialmente na virada do século XIX para o XX, quando a área virou um verdadeiro canteiro de obras. Surpreendem-nos a dinâmica do processo de urbanização e o ritmo das mudanças nos padrões de urbanidade desde então. O que hoje chamamos de "centro histórico" correspondia ao "perímetro urbano" e à zona efetivamente urbanizada em 1809, convertendo-se em "perímetro central" a partir de 1914-1916 (GLEZER, 1994, p. 164), por ocasião da primeira grande expansão da cidade.

O "perímetro urbano" de 1809 foi demarcado em função da Décima e envolvia somente as freguesias da Sé e de Santa Ifigênia, apresentando 1.281 imóveis e uma população oscilando em torno de 7.000 habitantes (BUENO, 2005, 2008). De 1872 a 1890 a população dobrou, de 31.385 para 64.934 habitantes, duplicando novamente de 1900 a 1920, de 239.820 para 579.033 habitantes. Em paralelo, a cidade se expandiu em todas as direções. Nossa memória não imagina o perfil da população e das atividades urbanas em tempos tão recuados, e as mudanças na vida urbana num curto período de tempo.

A interpretação da Décima Urbana de 1809 possibilitou um retrato da tessitura de São Paulo antes da sua primeira transformação e expansão, indiretamente lançando luz nos atores sociais detentores dos imóveis (BUENO, 2005, 2008). Espécie de recenseamento por escrito, a informatização e a espacialização dos dados revelaram uma cidade constrangida na "colina central", contendo apenas 1.281 imóveis predominantemente térreos e residenciais: $86 \%$ deles eram casas comuns de taipa de pilão (1.047), em meio a apenas 161 sobrados (13\%). No que diz respeito aos usos, 86\% (1.051) eram residências, $2 \%$ (26) lojas e 10\% (132) imóveis de uso misto. Curiosamente, 50\% (638) das edificações destinavam-se à renda de aluguel.

A Décima permitiu entrever que, na aparente homogeneidade do conjunto, a São Paulo colonial apresentava espaços especializados e espacializava o degradé social então vigente, contendo áreas mais e menos valorizadas. As zonas mais caras eram aquelas junto dos Largos da Sé, do Pátio do Colégio e ruas de uso misto a eles contíguas, concentrando o comércio e os sobrados da cidade. Já as casas térreas, predominantemente de porta e janela, ficavam na extremidade e junto das várzeas do Tamanduateí e Anhangabaú. Lote a lote, o estudo permitiu falar de mercado imobiliário em tempos recuados, mostrar as faces dos principais proprietários dos imóveis - em geral negociantes e mercadores -, algo a que a historiografia vinha dando pouca ênfase.

As mudanças no perímetro central num curto período de tempo se explicam em função das alterações no papel da cidade no contexto da Província e depois Estado de São Paulo. Nosso propósito neste ensaio é reconstituir parcialmente a feição dos imóveis, os proprietários, os inquilinos e as principais atividades desenvolvidas nos imóveis do centro, especialmente o comércio e os serviços na longa duração, variáveis eleitas para mensurar índices de urbanidade.

\section{O que revelam Censos e Décimas sobre as ruas de comércio da cidade?}

A historiografia recente sobre a história social e a urbanização no Brasil vem incluindo atores outrora invisíveis no debate. Por exemplo, a categoria genérica e anacrônica do que hoje denominamos de comerciantes vem ganhando refinamento (BARBUY, 2006; BORREGO, 2010). 
Censos e Décimas permitem resgatar a geografia do comércio e dos serviços em fins do período colonial, localizando os negociantes e mercadores (em geral proprietários dos imóveis e envolvidos com o comércio atacadista de longa distância) e os diversos segmentos relacionados com a venda a retalho e os oficiais mecânicos (em geral inquilinos).

É preciso salientar que a Décima de 1809 apresenta os imóveis, os proprietários, inquilinos, sua tipologia e localização. Os Censos não trazem a localização dos imóveis, mas permitem caracterizar o perfil social e as atividades dos proprietários e inquilinos, bem como o número de escravos e agregados que possuíam. Tratase, portanto, de documentações complementares, e seu cruzamento revela a "sociotopografia" (LE GOFF, 1992), isto é, a paisagem social da área central em tempos pretéritos.

Em 1809, na Rua Direita, por exemplo, dos 45 imóveis vinte eram sobrados (quatorze de uso misto: doze de uma loja e um andar; um de duas lojas e um andar; um de uma loja e dois andares). Apenas seis eram exclusivamente residenciais, em meio a dezoito prédios térreos (doze casas térreas simplesmente, quatro térreas de dois lanços, duas lojas). Os sobrados (n. 1 a 6 , $8,10,11,14,21,31,34,36,37,38,39,40,43,45$ ) concentravam-se próximos ao Largo da Sé, nas esquinas, entremeando-se com casas e lojas térreas. Segundo vêm revelando as pesquisas ainda inéditas do doutorando Nelson Braghittoni, muitos desses sobrados eram oriundos do século XVIII, herdados de importantes clãs de comerciantes setecentistas (BORREGO, 2010): Gaspar de Matos, Manuel Veloso, José Goes e Moraes, Manoel Mendes de Almeida e Angela Vieira.

A Rua Direita reunia o mais expressivo conjunto de negociantes, preferencialmente os de fazendas secas (tecidos). O Censo de 1798 revela que havia um único negociante de ferragens, um único negociante de molhados, além de traficantes de escravos, senhor de engenho, negociante de açúcar e café e tropeiros. No século XVIII e início do XIX, a maioria deles ali habitava e, por vezes, também ali exercia suas atividades mercantis. Entre os negociantes havia, por exemplo, Joaquim Jozé de Oliveira (n. 3, sobrado de uma loja e um andar, uso próprio; n. 44, térrea e fechada) que também aparece na Décima de 1809 como inquilino de D. Anna de Almeida na Rua do Comércio n. 25, num sobrado de cinco lojas e um andar, alugando provavelmente uma das lojas para desdobramento do seu negócio, o que significa que tinha lojas em dois endereços. Negociantes de fazenda seca do Rio de Janeiro havia o guarda-mor Vicente Ferreira de Oliveira (n.1, sobrado de uma loja e um andar, uso próprio), Manuel Gonsalves dos Santos e João Garcia da Fonseca (n. 41, térrea) e o coronel Joaquim Jozé Pinto de Moraes Leme (n. 23, sobrado). Negociante de escravos e senhor de engenho (com fábrica de açúcar em Jundiaí) havia o coronel Joaquim Jozé dos Santos (n. 10, sobrado de um andar, uso próprio; n. 24, sobrado fechado). Negociante de açúcar e café encontramos Jose Manuel de Sá (n. 45, sobrado de uma loja e um andar). Negociante de ferragens havia José Pinto Tavares (n. 8, sobrado de uma loja e um andar, uso próprio), que também era proprietário de outro sobrado de uma loja, dois corredores e um andar na Rua do Comércio n. 31, cujo corredor estava alugado. Negociante de molhados ali estava solitário Manuel Joaquim de Vasconcellos (n. 9, loja). A rua mesclava diversos usos como se pode ver, inclusive tropeiros que traziam bestas do Rio Grande do Sul e Curitiba para as feiras de Sorocaba, tais como Jozé Francisco de Salles (n. 21, sobrado de um andar) e Jozé Vaz de Carvalho (n. 31, sobrado uso próprio; n. 32, térrea cedida de favor para a sogra; n. 35, térrea alugada) que consta na Lista Nominativa de 1798 como coronel e morando na Rua Direita com a mulher, quatro filhos e 37 escravos. Na Rua Direita aparecem também como proprietários de imóveis alguns dos poucos bacharéis de Direito da cidade e ricas senhoras (viúvas ou solteiras) que viviam da renda de aluguel de seus imóveis e dos escravos de ganho. Bacharéis de Direito encontramos Dr. Manuel Eufrazio de Azevedo Marques (n. 37, sobrado alugado) e o Dr. Nicolao Pereira de C. Vergueiro (n. 14, sobrado alugado). Senhoras havia D. Gertrudes Velozo (n. 22, térrea, onde morava com suas duas irmãs solteironas) e D. Maria Francisca de Jesus (n. 26, vivendo de favor). A maioria dos imóveis estava ocupada, à exceção de um único terreno, um em obras, um arruinado e por isso inabitável, um fechado e um habitado gratuitamente.

Na Rua do Comércio (atual Álvares Penteado), por sua vez, constam quatorze prédios no lado esquerdo e vinte do lado direito, totalizando 34 imóveis (dez sobrados e 24 térreos). Fazendo jus à alcunha, na rua predominavam imóveis de uso misto; só cinco eram exclusivamente residenciais. A toponímia revela a presença marcante de um certo tipo de comércio, como se verá, estabelecimentos de naturezas diferentes daqueles da rua Direita. Havia imóveis contendo quatro ou cinco lojas, alugadas para diversos inquilinos. Os nomes dos proprietários são menos conhecidos que os da Rua Direita, envolvendo provavelmente comerciantes relacionados com a venda a retalho. As patentes militares também 
indicam tratar-se de um segmento social inferior. Destacam-se o tenente-coronel Matheos da Silva Bueno, residindo numa casa térrea de dois lanços (n.18) e proprietário de uma loja e um lanço (n. 30) alugada para o capitão Jozé de Freitas Saldanha, assim como o sargento-mor Jozé Vaz Francisco (n. 19). Outros comerciantes também ali dispunham de imóveis para uso próprio ou renda de aluguel, tais como Anastácio de Freitas Trancozo (térrea n. 10, uma loja e um lanço, alugada), Agostinho dos Santos Portela (térrea e um lanço, n. 17), José Antônio da Silva Paulista (sobrados de uma loja e um andar, n. 20 e 21), Manuel Lopes Coimbra (térrea de uma loja e um lanço, n. 27), Jose Pinto Tavares (uma loja, dois corredores e um andar, n. 31), este último negociante de ferragens. José Pinto Tavares provavelmente usasse parte desse imóvel (só um corredor estava alugado) para renda de aluguel, pois parece que a matriz dos seus negócios ficava junto da sua morada na Rua Direita n. 8 (sobrado de uma loja e um andar, uso próprio). Tipologia recorrente na Rua do Comércio, o imóvel de José Pinto Tavares apresentava dois corredores, um dos quais alugado para Francisco Vitorino de Saopaio, sendo que a "loja e o primeiro andar não tiveram alugador algum". Na Rua do Comércio aparece, portanto, uma tipologia nova, a de imóvel térreo com loja e um corredor ou sobrado com loja e dois corredores. Por vezes, só o corredor aparece alugado. Do que se trata? Ainda não podemos afirmar.

O cruzamento de Décima e Censo permite espacializar comerciantes menores outrora invisíveis. Revela também que outro ramo de atividades mercantis concentrava-se na Travessa do
Comércio (depois chamada de Rua da Quitanda), envolvendo treze imóveis térreos, quatro de uso misto e uma loja. Eram certamente quitandas, vendas, tavernas e botequins, daí o nome dado posteriormente ao logradouro. Gêneros da terra, molhados e mantimentos eram comercializados também na Travessa das Cazinhas (atual Rua do Tesouro), na qual se mesclavam sete sobrados a imóveis térreos e às tais dez Cazinhas pertencentes à Câmara e arrematadas por Jozé Mendes.

Por fim, na Rua do Rosario a Boa Vista, atual XV de Novembro, encontramos 73 imóveis, dentre os quais apenas treze sobrados (oito de uso misto), sete lojas e doze casas térreas de uso misto. Portanto ali se concentravam ao menos 32 estabelecimentos comerciais, certamente um pouco mais, pois as lojas estavam muitas vezes alugadas para mais de um inquilino, fato recorrente no período e subsequentes. Um caso interessante é o de Joaquim Jozé da Silva, proprietário de cinco lojas e um andar, parecendo usar somente uma delas e o andar, pois as demais aparecem alugadas para pessoas diferentes. Ele era ainda proprietário de dois outros imóveis na Rua do Comércio n. 3 e 4 (térrea e térrea de um lanço), ambos alugados. $O$ valor do aluguel de cada loja era $1 \$ 280$ réis por mês, o que nos permite inferir que as lojas eram alugadas por uma quantia paga mensalmente, como hoje, e nas ruas de comércio havia um preço médio de aluguel sempre abaixo dos da Rua Direita, a mais cara da cidade, concentrando os coronéis e negociantes mais importantes.

Figura 1: Edmund Pink. Sketch in the city - O Palácio da Sola, 1823. Aquarela, 18,5 x 40 cm. BM \& FBOVESPA S.A. Típica loja na rua do Comércio em São Paulo.

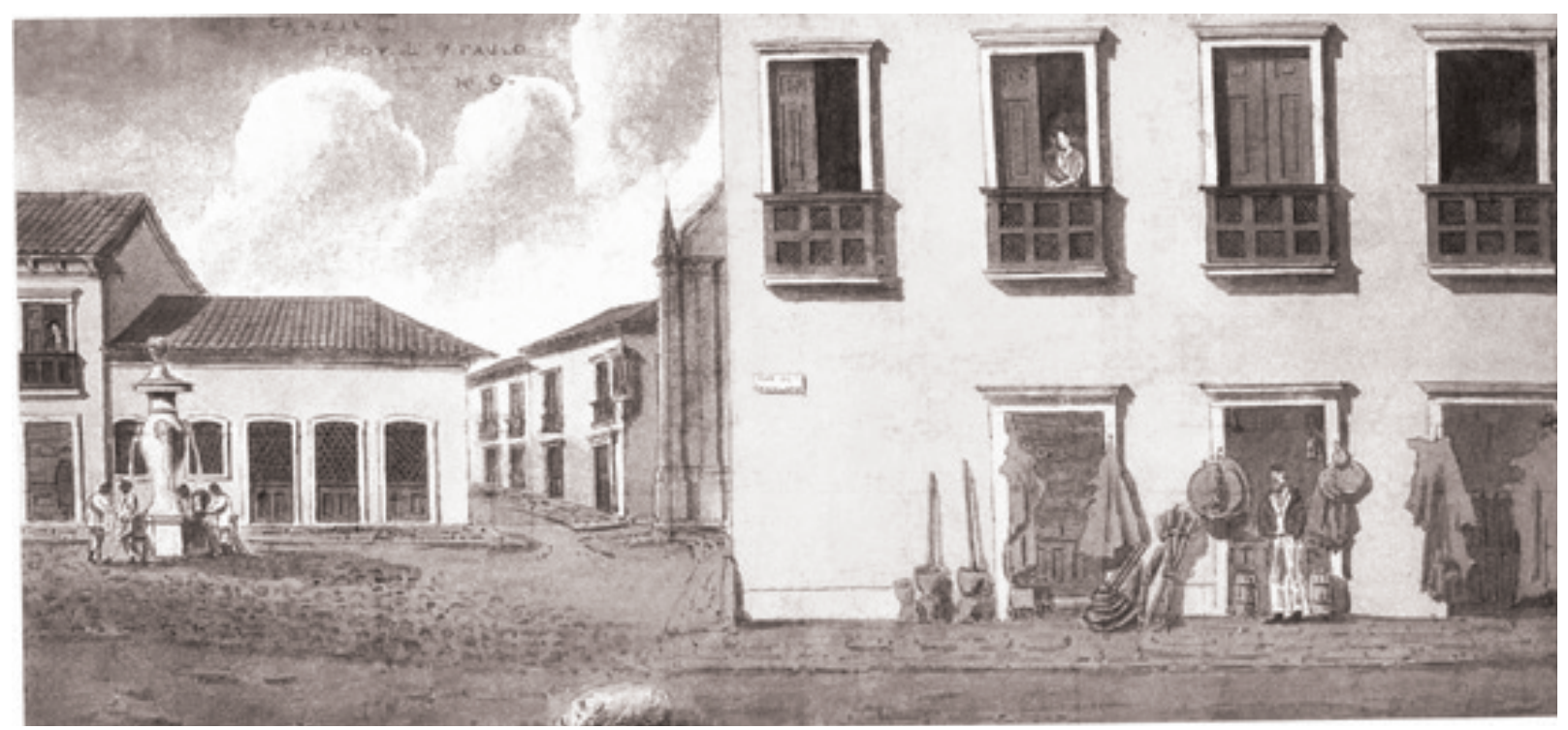


O Censo de 1798 revela a origem e destino dos produtos comercializados nas ruas supracitadas: de Curitiba-Sorocaba com destino a Mato Grosso e Goiás levavam-se bestas e fazendas secas (tecidos); de Itu e Campinas provinham o açúcar, o café e o anil, o primeiro embarcado em parte para Lisboa; de Jundiaí e arredores, vinham os mantimentos; do Rio de Janeiro, escravos, boticário, farinha, fazendas, ouro e outros negócios; de Santos, molhados, fazendas e peixes. O Censo de 1798 revela a quantidade e heterogeneidade dos estabelecimentos comerciais: 22 quitandas; dez vendas de produtos da terra; quatro vendas de produtos da terra e de fora; uma venda de louças da terra/quitanda; quatro vendas-botequim-botica; uma venda-engenho; duas vendas-gado; uma venda-café. Revela também outras atividades urbanas predominantes: um advogado; seis barbeiros-cabeleireiros; um caixeiro; oito carpinteiros-marceneiros; 66 costureiras; três ferreiros-ferradores; dezesseis funcionários públicos; vinte religiosos; quinze jornaleiros; quatro lavadeiras; cinco ourives; sete professores; 26 sapateiros-alfaiates; dois seleiros. Revela também que se os negociantes situavam-se, sobretudo, na Rua Direita e as vendas e quitandas, sobretudo, na Rua e Travessa do Comércio, na direção do Largo de São Gonçalo ficavam os celeiros-ferradores-ferreiros, bordadeiras-rendeiras e as costureiras (SANTOS, 2013, p. 123-125), portanto, os serviços, em geral deslocados para as bordas da cidade.

\section{Palimpsesto: a cidade de tijolo sobre a da taipa de pilão}

Marcos Rios (2005) ensaiou uma metodologia piloto no estudo do caso da Rua XV de Novembro, sobrepondo dados da Décima de 1809 aos do Arquivo Aguirra, dos projetos arquitetônicos da Série das Obras Particulares do AHSP e do Piqueri, a fotos antigas, espacializando-os nas plantas cadastrais do período. As pesquisas do doutorando Nelson Braghittoni seguem a mesma orientação metodológica, elegendo a Rua Direita como campo operatório, lote a lote, só que ampliando o recorte temporal para o século XVIII. Em ambos, nota-se que alguns lotes mereceram três ou até quatro edificações num curto período de tempo. Edifícios de tijolos e uso misto passam a mesclar salas de escritórios e consultórios, moradias, lojas, charutarias, restaurantes e cafés, substituindo os imóveis de taipa de pilão do período colonial.

As atividades terciárias exigidas pela "Metrópole do Café" cresceram exponencialmente. Entre 1776 e 1883, a cidade passou de 207 indivíduos envolvidos com o setor para 1.055 (em 1798), 1.916 (em 1836) e 36.901 (em 1893). Em 1883, São Paulo contava com 69 advogados, 32 médicos-cirurgiões, 10 engenheiros, 3 agrimensores, 33 empreiteiros de obras e 4 mestres de obras. De 130 casas de comércio existentes em 1883, passou para 5.832, em 1921/1922 (292 de artigos de importação, 106 confeitarias e pastelarias, 22 perfumarias, 86 joalherias, 32 relojoarias, 62 papelarias, 152 charutarias, 15 casas importadoras de automóveis, 30 estabelecimentos bancários, além de diversos hotéis). (BUENO, 2012, p. 36).

A dinâmica de mutação da cidade é incomum e nossa tese é que o investimento estatal foi bastante inferior ao do capital privado, responsável pela concreta destruição e reconstrução do veIho centro de taipa-de-pilão e introdução de novos usos e hábitos urbanos nos espaços, desde então um excelente negócio (BUENO, 2010).

Dados (BUENO, 2008) evidenciam um explosivo aumento dos preços dos terrenos no "triângulo central" (Ruas XV de Novembro, Direita e São Bento) entre 1916 (1.000\$000 réis o $\mathrm{m} 2), 1936$ $(4.500 \$ 000$ réis o $\mathrm{m} 2)$ e $1943(8.000 \$ 000$ réis o $\mathrm{m} 2$ ), o que é produto e vetor (numa relação dialética) da contínua aceleração das transformações arquitetônicas e urbanísticas e especialização ali do comércio e dos serviços de luxo. Constatou-se que o valor do m2 no "triângulo" era altíssimo comparativamente às outras zonas da cidade. Em 1914, o m2 nas ruas XV de Novembro, Direita e $S$. Bento tinha um valor médio de 1:000\$000 réis, ao passo que nos arredores imediatos decaía para $165 \$ 000$ réis, chegando a $23 \$ 500$ réis o $\mathrm{m} 2$ no "perímetro urbano" abaixo da "colina". No "perímetro suburbano" chegava a $3 \$ 000$ réis o $\mathrm{m} 2$, atingindo o valor de 100 réis no "perímetro rural" (BRITO, 1938). Também o valor locatício tornou-se muito atraente na área central, chegando a ser dezesseis vezes mais alto que na periferia da cidade. Esses dados explicam o interesse dos estratos sociais de maior poder aquisitivo em investir no centro, construindo imóveis de aluguel cada vez mais verticalizados. Explica, inclusive, o interesse do poder público (integrado por membros dessa mesma elite financeira) em investir em grandes obras de embelezamento e melhoramentos urbanos.

Na linha dos estudos de Heloísa Barbuy, pudemos constatar em incursões aos Almanaques que o comércio a partir de 1870 foi obra predominantemente de estrangeiros, deixando os veIhos "portugas" para trás. 
Na Décima Urbana de 1809 ficou claro que no período colonial o negociante e o mercador reuniam num único imóvel moradia e loja, em geral sendo proprietário dele. O Imposto Predial de 1876 revela que apenas Adolpho Nagel, Gustavo Sydow e Henrique Fox eram estrangeiros proprietários de imóveis no centro. A velha oligarquia segue sendo proprietária dos principais imóveis dali, mesclando-se muito paulatinamente a segmentos estrangeiros vinculados a ramos mais rentáveis, como ferrovias por exemplo. Esse é o caso de Guilherme Rudge, solitário em meio ao baronato predominante - Barão de Itapetininga, Barão de Piracicaba, Barão da Silva Gameiro, Barão de Sousa Queiroz, Barão de Tietê, Barão de Três Rios, Baronesa de Limeira - e a nomes expressivos como o de Manoel Rodrigues Jordão e Manoel Rodrigues Villares (Imposto Predial de 1876).

No Imposto Predial de 1886 vemos o universo ampliar-se, mas comparativamente aos dados publicados no Almanaque de 1890 (BUENO, 2012, p. 37) poucos estrangeiros inserem-se na lista de proprietários no centro, predominando ainda a velha oligarquia paulistana. Exceções são: João Adolpho Schritizmeyer, Domingos Paiva de Azevedo, José Elias Paiva, Luiz Bamberg, Adolpho Nagel, Henrique Luiz Levy e Jorge Seckler, só para citar os mais conhecidos. Em 1886, o centro parece manter-se nas mãos de um grupo social antigo, muitos dos nomes identificáveis desde a Décima de 1809: Barão de Piracicaba, Visconde de Vergueiro, Francisco José de Sampaio, José Antônio de Oliveira Mendes, Anna Brandina Prado Pereira Pinto, Maria da Glória Moura Jordão, Dr. Raphael Tobias de Aguiar, Conde de Três Rios, Maria Cantinho Gavião Peixoto, Visconde de São Joaquim, Barão de Souza Queiroz, Antônio Pinto do Rego Freitas, Baronesa de Limeira, Bernardo Avelino Gavião Peixoto, Raphael Aguiar Paes de Barros, Barão de Souza Queiroz, Conselheiro Antônio da Silva Prado, Elias Antônio Pacheco Chaves, Eleutério da Silva Prado, Firmino José Barbosa, José Arouche de Toledo, Eduardo Prates, só para citar alguns, em meio às Ordens religiosas e irmandades laicas - Convento do Carmo, Santa Casa de Misericórdia, Ordem Terceira do Carmo, Santo Antônio, Recolhimento de Santa Teresa, Mosteiro de São Bento.

Na Série Obras Particulares (1906-1914) o número de prédios para os quais foi solicitada autorização da Prefeitura para construção por comerciantes estrangeiros elevou-se consideravelmente, embora ainda muito aquém dos estabelecimentos publicados nos Almanaques. Comerciantes que solicitaram autorização de construção ou reforma no período estudado foram: Worms Irmãos, Luiz Bamberg, Antonio Luiz Garraux, Camisaria Especial, P. Birelmayer e Carlos Castellões, Fasano e Fazzini, Brasserie Paulista, Alcides Pertica, Luiz Levy, Carvalho Ramos \& Cia, Silvestre Noschese, o boticário Gustavo Shaw, Falchi Gianini e Cia, Oppenheim e Cia, Pharmacia Faraut, Comp. Brazil Express - Messenger Company, Heydenreich \& Irmãos, Bloch (Frères) e Cia, Cia de Industria e Comercio Casa Tolle, Firma Guinle e Cia, Pharmacia Ipiranga, Enrique Paiva, Loja Marcondes Piratininga, Weissflog Irmãos \& Cia, Luiz Médici, Baruel e Companhia, Casa Fretin, L. Grumbach \& Cia, Casa "Ao Preço Fixo", Guilherme Rathsam, Jorge Fuchs e Comp., entre outros desconhecidos. Nossa hipótese é que esses comerciantes-proprietários eram os usuários tanto das lojas como das moradias construídas nos andares superiores dos seus imóveis, mantendo uma tipologia recorrente no período colonial, a que estavam habituados nas suas cidades de origem.

O descompasso entre o número de estabelecimentos divulgados nos Almanaques e aquele publicado nas listas de Imposto Predial ou na Série Obras Particulares evidencia que a maioria dos comerciantes - majoritariamente estrangeiros - não dispunha de capital para comprar ou construir, alugando de terceiros tanto as lojas como os apartamentos que estavam sendo edificados ao gosto eclético francês no centro. Barbuy salienta a permanência das moradias nesses novos edifícios do início da Primeira República, diminuindo posteriormente. Habituados a morar no centro das cidades de onde vieram, junto de seus negócios, ao que tudo indica, seguiram o mesmo padrão no Brasil (mantendo contíguos moradia e trabalho), na contramão da elite social e econômica local que aderiu aos novos bairros exclusivamente residenciais dos subúrbios. A nosso ver, foram os estrangeiros majoritariamente os locatários tanto das lojas como de uma nova tipologia de apartamentos projetada no perímetro central, sobretudo a partir de 1902, nos edifícios de uso misto. As plantas localizadas no AHSP evidenciam a presença recorrente desse programa edilício, só não sabíamos a que público se destinava.

A seriação da documentação sugere ainda que, nessa época, a velha oligarquia paulistana (junto de uns poucos imigrantes endinheirados vinculados ao comércio, às fábricas - Matarazzo e Duchen -, aos loteamentos - Nothmann, Glette e Germaine Burchard - e às ferrovias) segue sendo a proprietária dos imóveis e promovendo a sua demolição e reconstrução, sendo os comerciantes - em geral estrangeiros - na sua maioria inquilinos das lojas e dos modernos 
Figura 2: Projeto para Joaquim Gil Pinheiro. Arquiteto: Maximilian Hehl, Rua São Bento n. 2. Tipologia recorrente no centro, mesclando comércio e moradia
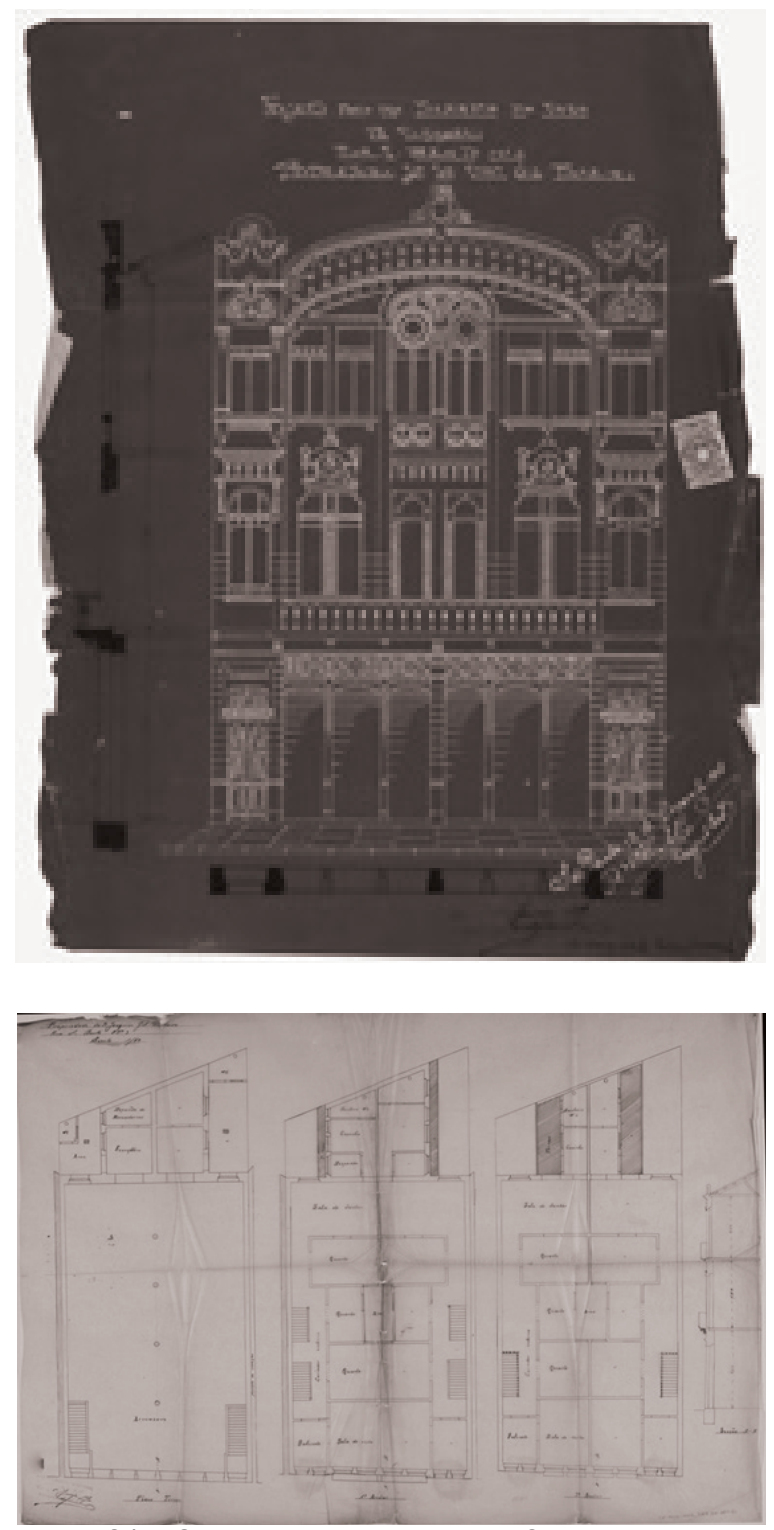

Fonte: Série Obras Particulares, 1908, AHSP.

apartamentos ainda não incorporados ao gosto da oligarquia e das camadas médias nacionais acostumadas a morar em moradias individuais.

A propaganda imobiliária veiculada nos jornais corrobora essa hipótese. $\mathrm{O}$ discurso publicitário buscava qualificar tais empreendimentos assemelhando-os a um "palacete" e aludindo ao discurso higienista, ideias associadas ao conceito de "progresso" e "modernidade" então em vias de afirmação. Interessante é o caso do "Palacete Nacim Schoueri", construído em 1930, destinado "particularmente ao pessoal do comércio" - situando-se a "3 minutos apenas da rua Quinze de Novembro". Embora destinado aos comerciantes, visava atingir "todas as classes", muitas ainda não afeitas a esse novo programa de habitação coletiva.
Figura 3: "Palacete Nacim Schoueri". Edifício de apartamentos e lojas destinado principalmente ao "pessoal do comércio".
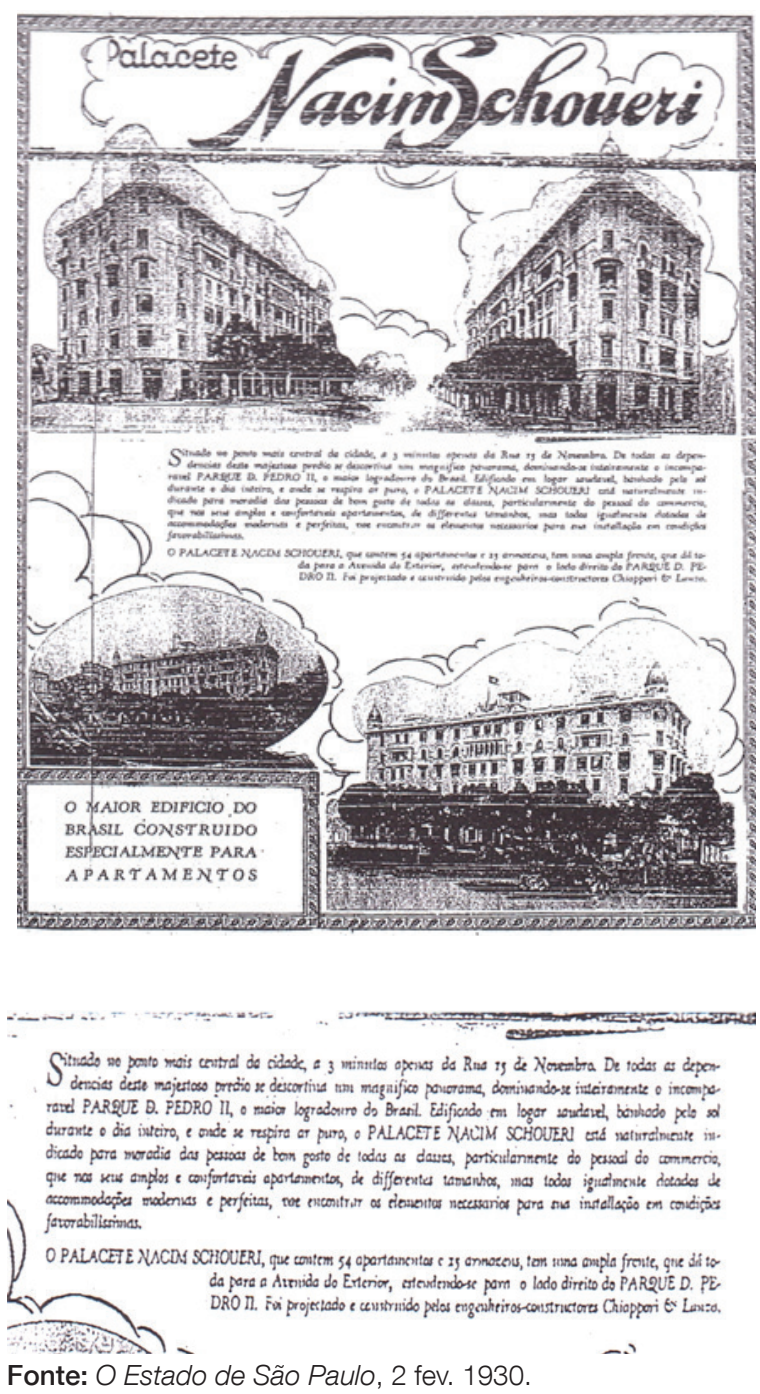

\section{Referências}

BARBUY, H. A cidade-exposição: comércio e cosmopolitismo em São Paulo, 1860-1914. São Paulo: EDUSP, 2006.

\section{In: \\ Seguindo Militão pelas ruas da cidade. Paulo: Cosac Naify, 2012.}

BORREGO, M. A. de M. A teia mercantil: negócios e poderes em São Paulo colonial (17111765). São Paulo: Alameda, 2010.

BRITO, R. C. Cadastro Imobiliário de São Paulo 1937-1938. São Paulo: União Paulista de Imprensa, 1938. 
BUENO, B. P. S. Tecido urbano e mercado imobiliário em São Paulo: metodologia de estudo com base na Décima Urbana de 1809. Anais do Museu Paulista: História e Cultura Material, n.13, p. 49-99, 2005.

. Questão fundiária e imobiliária na história da cidade colonial e imperial: estudo comparativo de São Paulo e Santos (1809-1840). Anais do IX SHCU, FAUUSP, set. 2006.

Aspectos do mercado imobiliário em perspectiva histórica: São Paulo, 1809-1950. São Paulo: FAUUSP, 2008.

A cidade como negócio: mercado imobiliário em São Paulo no século XIX. In: FRIDMAN, F; ABREU, M. (Org.). Cidades latino-americanas: um debate sobre a formação de núcleos urbanos. Rio de Janeiro: Casa da Palavra: FAPERJ, 2010. p. 145-165.

GLEZER, R. São Paulo, cem anos de perímetro urbano. História, São Paulo, v. 13, p. 155-166, 1994.

LE GOFF, J. O apogeu da cidade medieval. São Paulo: Martins Fontes, 1992.

MENESES, U. B. de. "O objeto material como documento", aula ministrada no curso "Patrimônio cultural: políticas e perspectivas", organizado pelo IAB/CONDEPHAAT em 1980. Mimeografado.

Plano Diretor do Museu Paulista da USP. São Paulo, 1990.

PARETO JÚNIOR, L. O cotidiano em construção: os "práticos licenciados" em São Paulo (1893-1933). 2011. Dissertação (Mestrado em Arquitetura e Urbanismo) - FAUUSP, São Paulo, 2011.

REIS, N. G. Notas sobre a evolução dos estudos de História da Urbanização e do Urbanismo. Cadernos de Pesquisa do LAP, n. 29, 1999.

. São Paulo: vila, cidade e metrópole. São Paulo: Via das Artes, 2004.

RIOS, F. M. C. Uma rua em três tempos: o caso da XV de Novembro em São Paulo (1809-1954). Iniciação Científica (Arquitetura e Urbanismo) FAUUSP, São Paulo, 2005.

SANTOS, A. C. Em obras: os trabalhadores da cidade de São Paulo entre 1775 e 1809. 2013. Dissertação (Mestrado em Arquitetura e Urbanismo) - FAUUSP, São Paulo, 2013.
SCHNECK, S. Formação do bairro do Bexiga em São Paulo: loteadores, proprietários, construtores, tipologias edilícias e usuários (18811933). Dissertação (Arquitetura e Urbanismo) FAUUSP, 2010.

TOLEDO, B. L. de. São Paulo: três cidades em um século. 2. ed. São Paulo: Duas Cidades, 1983. 
